\title{
Understanding Mechanisms of Change in the Development of Antisocial Behavior: The Impact of a Universal Intervention
}

\author{
Pol A. C. van Lier, ${ }^{1,2,3}$ Patricia Vuijk, $^{1}$ and Alfons A. M. Crijnen ${ }^{1}$
}

Received June 23, 2004; revision received December 15, 2004; accepted February 10, 2005

\begin{abstract}
The association between the development of antisocial behavior, affiliation with deviant friends, and peer rejection was tested with a preventive intervention; 664 boys and girls were randomly assigned to a universal classroom-based intervention targeting disruptive behavior or a control condition. Peer nominations of antisocial behavior, friends' antisocial behavior, and peer rejection were assessed annually for 4 years. A high, a moderate, and a stable low antisocial behavior trajectory were identified. Large reductions in antisocial behavior were found among intervention children who followed the high trajectory. These reductions coincided with affiliations with nondeviant peers and with decreases in peer rejection. The affiliation between deviant and nondeviant peers was initiated by nondeviant children. The results support a causal role of deviant friends and peer rejection in the development of antisocial behavior. The implications for our understanding of the mechanisms leading to reductions in antisocial behavior are discussed.
\end{abstract}

KEY WORDS: antisocial behavior; preventive intervention; peer affiliation; developmental trajectories.

An obvious contribution of prevention science is to study the impact of preventive intervention programs targeting antisocial behavior on immediate outcomes, such as reductions in antisocial behavior, and on distal outcomes, such as reductions in adolescent delinquency (for brevity, the term antisocial behavior, including physical aggression and disruptive behavior, will be used throughout unless more specific terms are meant). This has resulted in a growing body of preventive intervention studies, in which children's antisocial behavior and their subsequent risk for later maladjustment were effectively targeted (for an overview see Greenberg, Domitrovich, \& Bumbarger, 2001). A second, less well addressed capability of prevention science is to test models of the development of antisocial behavior (Kellam \& Rebok, 1992). Developmental models of antisocial behavior

\footnotetext{
${ }^{1}$ Department of Child and Adolescent Psychiatry, Erasmus MC - Sophia, Rotterdam, The Netherlands.

${ }^{2}$ Department of Developmental Psychology, Vrije Universiteit, Amsterdam, The Netherlands.

${ }^{3}$ Address all correspondence to Pol van Lier, Department of Developmental Psychology, Vrije Universiteit, Amsterdam, The Netherlands; e-mail: pac.van.lier@psy.vu.nl.
}

incorporate a variety of processes that are hypothesized to "cause" antisocial behavior. An assumption of these models is that many of these processes should change along with reductions in antisocial behavior. By nesting a preventive intervention in a longitudinal study on the development of antisocial behavior, this assumption can be tested. Moreover, such an approach provides insight into the processes that are associated with reductions in children's antisocial behavior (Cicchetti \& Toth, 1992). We nested the Good Behavior Game (GBG; Barrish, Saunders, \& Wolfe, 1969; Dolan, Jaylan, Werthamer, \& Kellam, 1989), a universal classroom-based preventive intervention, in a longitudinal study on the development of childhood antisocial behavior. The purpose of this study is to explore the impact of the GBG on (1) the developmental trajectories of children's antisocial behavior, and (2) two related domains of risk in children's social contexts, namely (a) the affiliation with deviant peers and (b) peer rejection as the punitive response of the larger peer-group.

This study is a follow-up to our prior study (van Lier, Vitaro, Wanner, Vuijk, \& Crijnen, 2005) in which the developmental trajectories of antisocial behavior from ages 7 to 10 years in the control-group children of the present 
sample were studied. There, we examined how the developmental trajectories of antisocial behavior coincided with the development of friends' antisocial behavior and with peer rejection over time. Three developmental trajectories were found: a high-increasing, a moderate, and a stable low antisocial behavior trajectory. In accordance with other studies we found that a small minority of children (10\%), almost exclusively boys, followed a high antisocial developmental trajectory (e.g., see Bongers, Koot, van Der Ende, \& Verhulst, 2004; Broidy et al., 2003). The level of antisocial behavior of these children diverged from their less antisocial counterparts across time (i.e., started at an elevated level and increased when children got older). Children who traveled along this trajectory chose friends whose antisocial behavior also diverged from the normative groups. Moreover, the children on the high antisocial path had very high probabilities of peer rejection over time, indexing their poor relations with normative peers. These children had the highest levels of self-reported aggressive and delinquent behavior at age 11 years. It was concluded that children who develop on a high antisocial behavior path are embedded in a social context that further increases their risk status. The high levels of peer rejection deprive them of positive connections and opportunities for practicing prosocial behavior with nondeviant peers. Instead, they are exposed to the learning, practicing, and reinforcement of deviant behavior through the affiliation with similarly diverging antisocial peers. These processes may well explain their diverging levels of antisocial behavior across time.

There is consensus that a variety of factors are associated with the development of antisocial behavior in children (Conduct Problems Prevention Research Group, 1992; Lahey, Waldman, \& McBurnett, 1999; Patterson, Reid, \& Dishion, 1992). In their search to identify the causes of antisocial behavior, researchers have focused on pre-existing characteristics within the child, such as learned behavioral or personal dispositions (Moffitt \& Caspi, 2001), and the influence of deviant friends or rejection by normative peers as the driving forces behind the emergence and maintenance of antisocial behavior (Asher \& Parker, 1989; Coie, Belding, \& Underwood, 1988; Elliott \& Menard, 1996; van Lier et al., 2005; Vitaro, Brendgen, \& Tremblay, 2000). With regard to the influence of deviant friends, Dishion, Patterson, and Griesler (1994) proposed that a process of confluence interaction, meaning that children tend to progressively reward behaviors that are similar to their own, and this process is seen as playing a key role in the selection of friends who share similar behavioral standards. As a result, antisocial children progressively affiliate with similarly antisocial peers. Such an affiliation has been shown to lead to high levels of antisocial behavior (Coie et al., 1999) and to juvenile delinquency (Lacourse, Nagin, Tremblay, Vitaro, \& Claes, 2003; Patterson, Dishion, \& Yoerger, 2000). A second negative consequence of this behavior is that children are placed at increased risk for the development of depressive problems (Fergusson, Wanner, Vitaro, Horwood, \& Swain-Campbell, 2003).

Active rejection by nonantisocial peers is conceptualized to reflect the punitive social response of nonantisocial peers to the behavior of antisocial children (Boivin \& Vitaro, 1995). Elliott, Huizinga, and Ageton (1985) posted that it is the weak bonding to nondeviant children that facilitates the high antisocial child's drift to similarly deviant children. Many studies have shown that antisocial children are likely to be rejected (e.g., see Deater-Deckard, 2001). The rejection by nondeviant peers deprives antisocial children of normative socialization experiences. Peer rejection has been shown to be an independent predictor of early starting conduct problems (Miller-Johnson, Coie, Maumary-Gremaud, \& Bierman, 2002) and of adolescent externalizing behavior and delinquency (Coie, Terry, Lenox, Lochman, \& Hyman, 1995; Miller-Johnson, Coie, Maumary-Gremoud, Lochman, \& Terry, 1999).

The assumption of developmental models is that specific risk variables cause children to follow specific developmental trajectories. This implies that changes in these risk variables should influence the course along which these children develop. A number of studies have shown that changes in the association between risk variables and outcomes were in part the result of the impact of a preventive intervention program on mediating variables. In the Montreal prevention experiment (Tremblay et al., 1991) it was found that the reduced risk for the development of conduct disorder at age 13 years among intervention children was mediated by the affiliation with less deviant peers from ages 10 to 12 years. The affiliation with less deviant peers was only found among intervention children who according to their teachers had reduced disruptiveness at 9 years of age (Vitaro, Brendgen, Pagani, Tremblay, \& McDuff, 1999). Similarly, the reduced levels of delinquency at age 13 among intervention children were mediated by reductions in the children's disruptiveness and improved parental supervision at age 11 years, and by the affiliation with nondeviant peers at age 12 years (Vitaro, Brendgen, \& Tremblay, 2001). Bierman et al. (2002) reported that the improved social preference scores among intervention children in the Fast Track prevention trial (Conduct Problems Prevention Research Group, 1992, 2002) were mediated by the improvements these intervention children showed on authority acceptance and prosocial behavior. Similar findings were reported for the Coping Power intervention (Lochman, Lenhart, \& Wells, 
1996; Wells, Lenhart, \& Lochman, 1996); the reduction in self-reported delinquency, found after 1 year of intervention was in part mediated by lower levels of parental inconsistency (Lochman \& Wells, 2002).

Despite their importance for our understanding of the mechanisms inducing change in antisocial children, these studies exclusively targeted high-risk children, thereby restricting the generalizability of the findings to other children. Moreover, such studies suggest that it is changes among the high-risk children that cause the reductions in their risk for later maladjustment. It may well be, however, that other processes, beyond the group of high-risk children contribute to the improvement of their behavior. For instance, in the study by Vitaro et al. (1999), the reduction in risk for developing conduct disorder among initially high-risk children was mediated by affiliations with less deviant peers. The affiliation with less deviant peers could have been caused by at-risk children ignoring similarly deviant children and selecting more normatively behaving friends. However, the opposite process is also possible: The improvement in peer relations could also have been caused by normatively developing children initiating the interaction and actively affiliating with at-risk children. It is therefore important to study the impact of a preventive intervention on children following high as well as low trajectories of antisocial behavior to test developmental theories and understand the mechanisms inducing a reduction in risk for later maladjustment problems.

In addition to testing the developmental link between antisocial behavior, affiliation with deviant peers, and peer rejection, we also wanted to contribute to the existing research on the effectiveness of the GBG intervention. The GBG is a classroom-based preventive intervention targeting aggressive and disruptive behavior. The GBG promotes prosocial behavior (1) by explicitly defining and systematically rewarding appropriate behavior, and (2) by facilitating the interaction between disruptive and nondisruptive children through a team-based approach. Through this, the GBG directly intervenes in the social context of children. The GBG was found to have a positive impact on the development of aggressive and disruptive behavior (Dolan et al., 1993; Ialongo et al., 1999; Ialongo, Poduska, Werthamer, \& Kellam, 2001; Kellam, Rebok, Ialongo, \& Mayer, 1994; Reid, Eddy, Fetrow, \& Stoolmiller, 1999), attention-deficit/hyperactivity problems, oppositional defiant problems, and conduct problems (van Lier, Muthén, van der Sar, \& Crijnen, 2004), to prevent the development of antisocial personality disorder (Petras, Kellam, Brown, $\&$ Ialongo, 2003), and to delay tobacco use in early adolescence (Kellam \& Anthony, 1998; Storr, Ialongo, Kellam, \& Anthony, 2002).
The following questions were addressed: (1) What is the impact of the GBG intervention on the developmental trajectories of peer-reported antisocial behavior? We hypothesized that the intervention would reduce antisocial behavior among children who travel on a high developmental trajectory. We also hypothesized that the intervention would prevent an increase of antisocial behavior for all other children. (2) What is the impact of the GBG intervention on the selection of friends and on peer acceptance? We hypothesized that a decrease in antisocial behavior among high antisocial children would be accompanied by affiliation with less antisocial peers and by a reduction in peer rejection. (3) Are the reductions in antisocial behavior due to intervention, also visible through other indices of maladjustment, such as attention problems, bullying, and victimization? Antisocial behavior often cooccurs with attention problems, bullying, victimization, and anxious/depressed problems. We therefore hypothesized that reductions in antisocial behavior would be accompanied by reductions in these behaviors. We also hypothesized that victimization would be reduced among children who themselves were not high on antisocial behavior and that such reductions would also result in lower levels of anxious/depressed problems among these children.

\section{METHOD}

\section{Sample}

Analyses were performed on children attending 13 elementary schools in the metropolitan areas of Rotterdam and Amsterdam, the Netherlands. All first-grade children who moved on to second grade in 1999 were eligible for inclusion. Of the 794 first graders, 722 were included by virtue of this criterion. An additional 22 children who repeated second grade, and moved into the study cohort, were included, making the total sample 744 children. All 744 parents or parent substitutes were approached to obtain written informed consent, and $666(89.5 \%)$ of them agreed to let their child participate in the study. Two children were excluded from the current study because they moved away from a study school before participating in the peer-assessments. Sixty-nine percent of the children were Caucasian, $10 \%$ Turkish, 9\% Moroccan, 5\% Surinam/Dutch Antillean, and 7\% from other ethnic groups. Fifty-one percent of the children were male, which was similar among the ethnic groups $\left(\chi^{2}(7, N=664)=4.67, p>.05\right)$. Nonparticipation in the study was not related to the child's gen$\operatorname{der}\left(\chi^{2}(1, N=664)=0.8, p>.05\right)$ or the ethnicity 
$\left(\chi^{2}(1, N=664)=1.8, p>.05\right)$ of the child. Thirtysix percent of all children were from low SES families, which was defined as caretakers being unemployed or having a low skill job and/or having completed only elementary school or less. The SES distribution of the sample reflected the SES distribution of the Netherlands (Netherlands Central Bureau of Statistics, 1999). The mean age of the children at baseline was 6.9 years $(S D$ 0.6). A total of 206 children were missing one or more assessments because of grade retention, moving away from school and because one class refused to participate in the last assessment (fourth grade); $96 \%$ of the children participated in at least two assessments. Children who dropped out of the study had higher levels of antisocial behavior $(F(1,643)=21.3, p<.05)$, affiliated with children with higher levels of antisocial behavior $(F(1,638)=8.3, p<.05)$, and were more likely to be rejected $\left(\chi^{2}(1, N=664)=11.9, p<.05\right)$ at age 7 years.

\section{Design}

Each of the 13 schools included at least two firstgrade classes at the start of the project. The baseline assessments were completed in first grade. During the summer break, when second-grade class compositions were known, classes within each school were randomly assigned to the intervention or control condition. Of the 31 classes in the 13 schools, 16 were assigned to the intervention condition and 15 to the control condition, resulting in 371 children who received the GBG program and 295 control-group children. The GBG intervention started in the fall of second grade. Classroom composition remained the same over the 2-year intervention period for $90.4 \%$ of the children.

\section{Preventive Intervention}

The Good Behavior Game is a classroom-based behavior management strategy that promotes prosocial behavior and reduces aggressive and disruptive behavior. The goal of the GBG is to create a safe and predictable classroom environment. Teachers discuss the necessity of formulating class rules and select with their students the rules for their class. The positively formulated rules are accompanied by pictograms. After observing children on well-defined behaviors in the classroom, teachers assign children to one of three or four teams. Teams include equal numbers of disruptive and nondisruptive children. Children are encouraged to manage their own and their teammates behavior through a process of group reinforcement and through mutual self-interest. Each team receives a number of cards and teams are rewarded when at the end of a 15-60-min period at least one card remains. Teachers take a card when a student violates one of the chosen rules. Teams and students are always rewarded with compliments.

In the first intervention year, the GBG was implemented in three different stages. In the introduction phase the GBG was played three times a week for approximately $10 \mathrm{~min}$. In addition to the compliments, winning teams also received tangible rewards (e.g., a sticker) directly after each game. In the expansion phase, teachers were encouraged to expand the duration of the GBG (up to three 1-hr sessions per week), expand the settings in which the GBG was played, and expand the behaviors targeted by the GBG. Rewards were delayed until the end of the week and, later, until the end of the month. This phase lasted until the early spring of the school year. In the generalization phase, emphasis was on promoting prosocial behavior outside GBG moments by explaining to children that the rules used during the GBG were also applicable when the game was not in process. Children received compliments for appropriate behavior by their teachers. The GBG-sessions were used as a booster. The same three phases were used in the second intervention year, but, because children were already familiar with the GBG, teachers swiftly moved to the expansion and generalization phase.

The GBG was played in second and third grade. Teachers received two afternoons of GBG training prior to the intervention and one afternoon of instruction in the middle of the year. During the first intervention year, teachers were coached in their classroom during ten 60-min classroom observations by well-trained advisors from the school advisory services. During the second intervention year, teachers were either supervised during 10 school visits by these advisors or were supervised by their schools' internal supervisor. Adherence to the GBG protocol was described previously (van Lier et al., 2004). Despite differences in implementation fidelity, an intention to treat approach was used in the analyses.

The GBG had to be adapted for use in the Dutch school system to ensure a proper implementation (van der Sar, 2002; van der Sar \& Goudswaard, 2001). In contrast to the U.S. GBG, Dutch teams do not compete for weekly winners and children violating GBG rules are not mentioned by the teachers. Also, children are encouraged to actively support team members to behave according to the (GBG) class rules.

\section{Measures}

Peer-nominations of antisocial behavior at ages 710 years were obtained with four behavioral descriptions. 
Children were asked to nominate all classmates of either sex that fit each of four descriptions: Starts fights, Angers easily, Says mean thing to peers, and Is disruptive (Coie \& Dodge, 1988). The four scores were divided by the number of children in the class minus one (children were not allowed to nominate themselves) and then summed to a total score. Cronbach's $\alpha$ ranged from .92 to .94 over the four assessments. Confirmatory factor analyses revealed that the item Starts fights was the core item of the scale.

Friends' antisocial behavior at ages 7-10 years was computed using the following procedure. Children were asked to nominate the three peers they liked most in their classroom at each assessment. These three children were considered the child's friends. Each of these friends had an antisocial behavior score, based on the peer-nomination of antisocial behavior scores as described above. The average of the antisocial behavior scores of these three children was used as the friends' antisocial behavior score.

Peer rejection at ages 7-10 years was based on a combination of liked-most and liked-least nominations (Coie \& Kupersmidt, 1983). Children were asked to nominate the three children in their class who fitted liked-most and liked-least descriptions best. Liked-most and likedleast scores were standardized within the classroom and standardized social preference scores were computed by subtracting the liked-most $z$ score from the liked-least $z$ score. This social preference score was then standardized within the classroom. "Rejected" children had a social preference score less than $-1.0 S D$, a standardized likedmost score less than zero, and a standardized liked-least score greater than zero. All remaining children were considered "not rejected." The 1-year stability of rejection was $.53, p<.01$.

\section{Correlates and Consequences}

Peer-nominations of relational bullying were obtained at age 10 years with five behavioral descriptions (e.g., This child tries to exclude or keep certain people from being in their group when doing things together; Crick, 1997). Cronbach's $\alpha$ was .89 .

Children's self-reports of victimization of overt and relational bullying at age 11 years were obtained with the Social Experience Questionnaire (SEQ; Crick \& Grotpeter, 1996). The SEQ consists of the scales Relational Victimization (e.g., How often does another kid say they won't like you unless you do what they want you to do?) and Overt Victimization (e.g., How often are you hit by another kid?). Cronbach's $\alpha$ was .64 for Relational Victimization and .63 for Overt Victimization.
Children's self-reported behavior problems over the last 2 months were assessed at age 11 years with theYouth Self Report (YSR; Achenbach, 1991). The YSR contains a list of 120 problem items. The scales Anxious/Depressed, Attention Problems, and Aggressive Behavior were used. The YSR has shown adequate reliability and validity in The Netherlands (Verhulst, van der Ende, \& Koot, 1997).

\section{Statistical Approach}

The analyses were carried out in four stages. We first employed growth modeling to determine the model needed to adequately describe the development of antisocial behavior and friends' antisocial behavior for intervention- and control-group children. Growth modeling estimates mean growth factors, i.e., initial status (intercept) and change (linear and if needed quadratic slope), and captures individual variation around these growth factors by the estimation of factor variances.

In the second stage of the analyses, developmental trajectories were estimated on control-group children only through Growth Mixture Modeling (GMM; Muthén, 2001; Muthén \& Muthén, 2000; Muthén \& Shedden, 1999). The objective of GMM is to find the smallest number of classes of individuals with similar developmental trajectories of antisocial behavior. GMM estimates mean growth factors for each class of children and captures individual variation around these growth factors by the estimation of factor variances. The antisocial behavior trajectories were identified in our previous study (van Lier et al., 2005) and were a high and increasing, an intermediate, and a stable low trajectory.

In the third stage of the analyses, intervention-group children were included in the model. For this we used General Growth Mixture Modeling (GGMM; Muthén \& Muthén, 2000) which allows for combinations of models. In this framework we accounted for the impact of the GBG intervention on the course of children's antisocial behavior by regressing the slopes of the three developmental trajectories on intervention status (Muthén et al., 2002).

In the fourth and final stage, the developmental trajectories of friends' antisocial behavior were included in the model. The development of friends' antisocial behavior was estimated for each of the three antisocial behavior trajectories. As for antisocial behavior, the slopes of the friends' antisocial behavior trajectories were regressed on intervention status to account for the impact of the GBG. The parameter estimates were controlled for gender. The estimated parameters of this final model were: (1) latent class membership probabilities, which gives the probability of each individual belonging to each of the classes, 
(2) the means and variances of the growth factors (intercept, slope, and quadratic slope) of children's antisocial behavior for each of the classes, (3) the means and variances of the growth factors of friends' antisocial behavior for each of the classes, and (4) estimates of the regression coefficient of the GBG on the slopes of children's own and friends' antisocial behavior scores for each of the classes. The standard errors were corrected for nesting of children within classrooms.

The overall GGMM, the separate GMM, and the growth models were analyzed with Mplus 3.0 (Muthén \& Muthén, 1998-2004). The missing data module was used to optimally use the available data and to take into account that children who were lost to follow-up had higher peer-nominated antisocial behavior at age 7 years than children who remained in the study. The impact of the GBG on the correlates and consequence measures-peernominations of bullying age 10, self-reports at age 10 and 11 years - was tested through Multivariate Analyses of Variance (MANOVA).

\section{RESULTS}

\section{Descriptive Statistics}

Mean peer-nominated antisocial behavior scores (with standard deviations in parentheses) were .74 (.66), $.86(.82), .69(.77)$, and .45 (.60) from the ages $7-10$ years, respectively. The correlations between the repeatedly assessed peer nominations of antisocial behavior ranged from .68 to $.86(p<.01)$. Mean friends' antisocial behavior scores (standard deviation in parentheses) were
$.63(.46), .66(.51), .53(.48)$, and $.37(.41)$ from ages $7-$ 10 , respectively. The correlations between the repeatedly assessed friends' antisocial behavior scores ranged from .56 to $.33(p<.01)$.

\section{Mean Differences Between GBG and Control-Group Children}

Peer-nominated antisocial behavior and relational bullying, self-reported victimization at age 10 years, and self-reported emotional and behavioral problems at age 11 years for control- and intervention-group boys and girls are presented in Table I. We used Multivariate Analyses of Variance (MANOVA) to test for overall differences as a function of gender and intervention. The significant estimate for gender and intervention status indicated differences in these ratings between control- and intervention-group boys and girls. We then performed separate MANOVA's at each assessment to optimally use the data. Boys had higher ratings on peer-nominated antisocial behavior and relational bullying, and on self-reported aggressive behavior and overt victimization. Children in the GBG intervention condition had lower levels of peer-nominated relational bullying and self-reported victimization of overt and relational bullying. In addition, positive effects of the GBG intervention were found on self-reported anxious/depressed problems at age 11 years. Effect sizes, expressed as Cohen's deviance (Cohen's $d$ ) were calculated to assess the clinical relevance of the differences between intervention- and control-group children. All effect sizes were either small $(d<.20)$ or in the small to medium range (Cohen, 1988).

Table I. Peer-Nominated and Self-Reported Means of Antisocial Behavior, Relational Bullying,Victimization, and Emotional and Behavior Problems for Control-Group and GBG-Children

\begin{tabular}{|c|c|c|c|c|c|c|c|c|c|c|c|c|}
\hline & \multicolumn{8}{|c|}{ Samples } & & & & \\
\hline & \multicolumn{4}{|c|}{ Control } & \multicolumn{4}{|c|}{ GBG } & \multicolumn{4}{|c|}{ Test } \\
\hline & \multicolumn{2}{|c|}{ Boys } & \multicolumn{2}{|c|}{ Girls } & \multicolumn{2}{|c|}{ Boys } & \multicolumn{2}{|c|}{ Girls } & \multicolumn{2}{|c|}{ Gender } & \multicolumn{2}{|c|}{ GBG } \\
\hline & $M$ & $S D$ & $M$ & $S D$ & $M$ & $S D$ & $M$ & $S D$ & $F$ & $\mathrm{ES}$ & $F$ & $\mathrm{ES}$ \\
\hline \multicolumn{13}{|c|}{ Peer-nominated (age $10, n=479$ ) } \\
\hline Antisocial behavior & 0.69 & 0.73 & 0.26 & 0.40 & 0.68 & 0.68 & 0.15 & 0.20 & $89.1^{* *}$ & .89 & 1.4 & - \\
\hline Relational bullying & 0.48 & 0.49 & 0.42 & 0.43 & 0.41 & 0.44 & 0.32 & 0.33 & $4.4^{*}$ & .19 & $4.5^{*}$ & .20 \\
\hline \multicolumn{13}{|l|}{ Self-report (age 10, $n=567$ ) } \\
\hline Overt victimization & 10.4 & 3.26 & 9.51 & 2.91 & 9.31 & 3.06 & 8.42 & 2.70 & $12.2^{* *}$ & .29 & $18.5^{* *}$ & .35 \\
\hline Relational victimization & 10.3 & 3.28 & 10.1 & 3.28 & 9.48 & 3.03 & 9.65 & 3.27 & 0.0 & - & $6.3^{*}$ & .22 \\
\hline \multicolumn{13}{|l|}{ Self-report (age $11, n=496$ ) } \\
\hline Anxious/depressed & 5.13 & 5.14 & 5.59 & 4.69 & 4.58 & 4.34 & 4.44 & 4.00 & 0.2 & - & $4.3^{*}$ & .18 \\
\hline Attention problems & 4.42 & 3.31 & 4.31 & 3.10 & 3.81 & 3.02 & 3.98 & 2.72 & 0.1 & - & 2.9 & - \\
\hline Aggressive behavior & 6.97 & 5.93 & 5.48 & 4.29 & 6.09 & 4.93 & 5.39 & 4.70 & $5.8^{*}$ & .21 & 1.1 & - \\
\hline
\end{tabular}

Note. Gender $\times$ GBG interaction was not significant at $p<.05$. GBG $=$ Good Behavior Game. ES $=$ Effect Size $($ Cohen's $d)$.

${ }^{*} p<.05 ;{ }^{* *} p<.01$. 


\section{Developmental Models of Antisocial Behavior and Friends' Antisocial Behavior}

We first explored the model that was needed to describe the development of children's antisocial behavior with age. It showed that a quadratic term was needed to describe this development for both control-group and intervention-group children. Freely estimating the variance of the continuous growth factors and covariance between the growth factors improved model fit. Model fit was improved when the variance of the observed antisocial behavior score was estimated freely at each assessment. The final multiple group model (control and GBG) had a good fit to the data (CFI $=.99$, TLI $=$ .96). We then explored the model that was needed to describe the development of friends' antisocial behavior with age. For control-group children, a linear term was sufficient. The development of friends' antisocial behavior for intervention-group children, however, was best described using a quadratic term. The final model of friends' antisocial behavior, with time-specific variances of the observed scores fitted the data well (CFI $=.99$, TLI $=.97)$.

\section{Mixture Modeling}

We then moved on to the estimation of distinct developmental trajectories. The three developmental trajectories of children's antisocial behavior as found in controlgroup children in our previous study served as a starting point for these analyses. These developmental trajectories were determined as follows: the variances of the continuous growth factors and the covariance between the growth factors were initially set to zero, to find the optimal number of developmental trajectories (Muthén \& Muthén, 1998-2004). A two-class (BIC = 1593), threeclass $(\mathrm{BIC}=1332)$, and four-class solution $(\mathrm{BIC}=1242)$ were fitted. We then tested whether random variations in the growth factors and indicator variance improved model fit in the solutions with the smallest BIC (i.e., the threeand four-class solutions. The optimal three- and four-class solutions had similar fit $(\mathrm{BIC}=772)$. We therefore chose the more parsimonious three-class model (van Lier et al., 2004).

We included intervention-group children in the third stage of the analyses. The slopes were regressed on intervention status to allow for the impact of the GBG on the growth parameters. In the fourth and final stage, the development of friends' antisocial behavior was added to the model and the slopes of friends' antisocial behavior were regressed on intervention status. The development of friends' antisocial behavior was estimated for each of the three antisocial behavior trajectories. To test the stability of this final model, 100 random perturbations of specified starting values were generated by the program. An optimization was carried out by performing 20 iterations for each of the starting values. The ending values from the optimization with the highest loglikelihood were used as the starting values for the 20 final-stage optimizations. The results showed that despite different starting values, similar model solutions were obtained, indicating that the final model was stable.

To study how loss to follow-up impacted the estimation, the final model was run including only children with complete data. Slightly fewer children were classified in the high antisocial developmental trajectory, as expected because loss to follow up was related to higher levels of antisocial behavior at age 7 years. Nevertheless, parameter estimates were highly similar to those in the model using all available data. Missing data did therefore not impact model estimation and the model using all available data was used. The distribution of control-group and intervention-group children was similar between the three classes $\left(\chi^{2}(2, N=664)=2.5, p>.05\right)$. All presented results are based on the model from the fourth stage of the analyses.

\section{Developmental Trajectories of Antisocial Behavior: Impact of the GBG Intervention}

The developmental trajectories of antisocial behavior are given in Fig. 1 (top), raw antisocial behavior scores for children in each of the developmental trajectories are in Table II. Ten percent of all children followed the high antisocial behavior trajectory (class 1), $92 \%$ were boys. These children had the highest antisocial behavior scores of all children at age 7 years. Control-group children showed increasing levels of antisocial behavior with age, which stabilized at a score of around 2.4. Intervention children initially followed the same developmental course as their control-group counterparts. However, with age, their level of antisocial behavior started to diverge from controlgroup children (i.e., it showed a decrease with time). The size of the mean difference in antisocial behavior between control- and intervention-group children at age $10, d=1.2$, was large (Cohen, 1988). Because only five girls followed this trajectory, gender differences were not analyzed.

Fifty-two percent of all children ( $66 \%$ boys) followed a moderate antisocial behavior trajectory (class 2). These children had intermediate levels of antisocial behavior at age 7 years, which decreased thereafter. Two-third of all boys in the sample followed this trajectory, which we thereafter referred to as a normative trajectory for boys. 

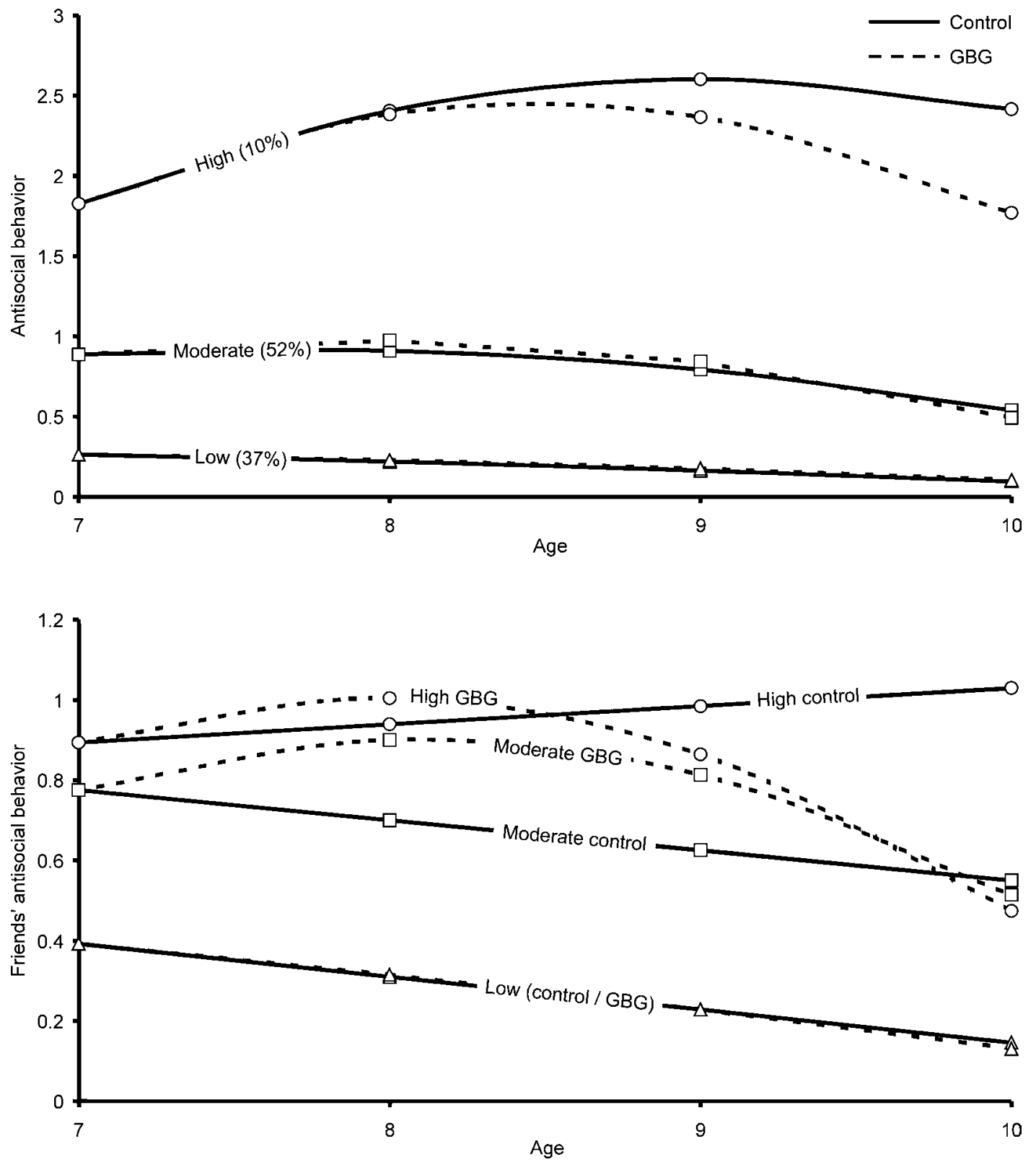

Fig. 1. Developmental trajectories of antisocial behavior (top) and friends' antisocial behavior (bottom) for control-group and GBG-children for children following a high, moderate, and low developmental trajectory of antisocial behavior.

The GBG did not have an impact on the course of antisocial behavior for children on this trajectory. The effects of gender on the parameter estimates are presented in Table III. To assess gender differences in GBG impact, the interaction term GBG $\times$ gender was entered. This term was not significant at $p<.05$ and therefore was deleted from the model. Boys on the moderate trajectory did have higher levels of antisocial behavior than girls as shown by the impact of gender on the intercept.
The final $38 \%$ of the sample, including $78 \%$ girls, followed a low antisocial developmental trajectory (class $3)$. These children had a low level or even absent levels of antisocial behavior throughout their development. Sixty-one percent of all girls in the sample followed this trajectory, which we thereafter referred to as normative for girls. The GBG did not have an impact on the development of antisocial behavior in these children. Boys on the low antisocial behavior trajectory had 
Table II. Mean Antisocial Behavior and Friends' Antisocial Behavior Scores, Test Statistics, and Effect Size of Mean Difference for Children Following a High $(n=64)$, Moderate $(n=347)$, or Low $(n=253)$ Developmental Trajectory

\begin{tabular}{|c|c|c|c|c|c|c|c|c|c|c|c|c|c|c|c|c|c|c|}
\hline & \multicolumn{6}{|c|}{$\begin{array}{l}\text { High (total sample, } \\
\left.10 \% ; \text { boy }^{a}, 92 \%\right)\end{array}$} & \multicolumn{6}{|c|}{$\begin{array}{l}\text { Moderate (total sample, } \\
52 \% \text {; boy }{ }^{a}, 66 \% \text { ) }\end{array}$} & \multicolumn{6}{|c|}{$\begin{array}{c}\text { Low (total sample, } 38 \% \text {; } \\
\text { percentage boy }{ }^{a}, 22 \% \text { ) }\end{array}$} \\
\hline & \multicolumn{2}{|c|}{ Control } & \multicolumn{2}{|c|}{ GBG } & \multicolumn{2}{|c|}{ Test } & \multicolumn{2}{|c|}{ Control } & \multicolumn{2}{|c|}{ GBG } & \multicolumn{2}{|c|}{ Test } & \multicolumn{2}{|c|}{ Control } & \multicolumn{2}{|c|}{ GBG } & \multicolumn{2}{|c|}{ Test } \\
\hline & $M$ & $S D$ & $M$ & $S D$ & $F$ & ES & $M$ & $S D$ & $M$ & $S D$ & $F$ & ES & $M$ & $S D$ & $M$ & $S D$ & $F$ & ES \\
\hline \multicolumn{19}{|c|}{ Antisocial Behavior } \\
\hline Age 7 & 1.95 & 0.78 & 1.91 & 0.56 & - & & 0.87 & 0.53 & 0.87 & 0.53 & - & - & 0.26 & 0.19 & 0.25 & 0.19 & - & - \\
\hline Age 8 & 2.54 & 0.62 & 2.46 & 0.63 & - & & 0.99 & 0.66 & 1.03 & 0.63 & - & - & 0.26 & 0.20 & 0.22 & 0.19 & - & - \\
\hline Age 9 & 2.56 & 0.59 & 2.46 & 0.49 & - & & 0.74 & 0.61 & 0.82 & 0.56 & - & - & 0.15 & 0.12 & 0.17 & 0.16 & - & - \\
\hline Age 10 & 2.33 & 0.34 & 1.87 & 0.42 & 11.1 & 1.22 & 0.56 & 0.48 & 0.47 & 0.40 & - & - & 0.09 & 0.11 & 0.10 & 0.11 & - & - \\
\hline \multicolumn{19}{|c|}{ Friends' antisocial behavior } \\
\hline Age 7 & 0.87 & 0.53 & 0.93 & 0.53 & - & & 0.73 & 0.43 & 0.79 & 0.47 & - & - & 0.40 & 0.29 & 0.38 & 0.32 & - & - \\
\hline Age 8 & 0.93 & 0.45 & 1.00 & 0.56 & - & & 0.76 & 0.54 & 0.92 & 0.50 & 7.6 & .30 & 0.35 & 0.23 & 0.32 & 0.25 & - & - \\
\hline Age 9 & 0.86 & 0.71 & 0.85 & 0.54 & - & & 0.61 & 0.46 & 0.81 & 0.49 & 13.1 & .42 & 0.22 & 0.18 & 0.22 & 0.16 & - & - \\
\hline Age 10 & 1.15 & 0.87 & 0.45 & 0.34 & 12.3 & 1.06 & 0.55 & 0.43 & 0.52 & 0.41 & - & - & 0.14 & 0.13 & 0.12 & 0.11 & - & - \\
\hline \multicolumn{19}{|c|}{ Rejection \% } \\
\hline Age 7 & 44 & & 46 & & - & - & 13 & & 10 & & - & - & 3 & & 1 & & - & - \\
\hline Age 8 & 62 & & 72 & & - & - & 16 & & 15 & & - & - & 1 & & 0 & & - & - \\
\hline Age 9 & 47 & & 74 & & $3.6^{b}$ & & 15 & & 14 & & - & - & 0 & & 2 & & - & - \\
\hline Age 10 & 75 & & 40 & & 5.2 & .84 & 14 & & 13 & & - & - & 0 & & 1 & & - & - \\
\hline
\end{tabular}

Note. Test statistics and effect sizes are given for means different at $p<.05 . \mathrm{ES}=$ effect size (Cohen' $d$ ).

${ }^{a}$ Gender distribution between classes is different $\left(\chi^{2}(2, N=664)=159.0, p<.05\right)$.

${ }^{b} p<.10$.

slightly higher levels of antisocial behavior than girls (see Table III).

\section{Friends' Antisocial Behavior and Peer Rejection: Impact of the GBG Intervention}

The development of friends' antisocial behavior based on whether target children were on the high (class 1), moderate (class 2), and low antisocial behavior trajectory (class 3) are presented in Fig. 1 (bottom). Control-group children who followed the high developmental trajectory affiliated with friends whose antisocial behavior was stable over time. In contrast, GBG-children on the high developmental path initially chose antisocial children as their friends. At age 10, however, the level of friends' antisocial behavior of class 1 controlgroup children was significantly higher than the friends'

Table III. Percentage of Total Sample, Percentage of Males, and Impact of Gender on Growth Parameters of Antisocial Behavior and Friends' Antisocial Behavior

\begin{tabular}{|c|c|c|c|c|c|}
\hline & \multicolumn{5}{|c|}{ Developmental trajectory } \\
\hline & \multirow{2}{*}{$\begin{array}{l}\text { High (sample, } \\
(10 \%, \text { male, } 92 \%)\end{array}$} & \multicolumn{2}{|c|}{$\begin{array}{c}\text { Moderate (sample, } \\
52 \% \text {, male, } 66 \%)\end{array}$} & \multicolumn{2}{|c|}{$\begin{array}{l}\text { Low (sample, } \\
38 \% \text {, male, } 22 \text { ) }\end{array}$} \\
\hline & & Est. & $S E$ & Est. & $S E$ \\
\hline \multicolumn{6}{|l|}{ ASB: boys vs. girls } \\
\hline Intercept & - & 0.26 & $0.04^{* *}$ & 0.07 & $0.03^{*}$ \\
\hline Linear slope & - & -0.06 & 0.07 & -0.04 & 0.03 \\
\hline Quadratic slope & - & 0.01 & 0.02 & 0.00 & 0.01 \\
\hline \multicolumn{6}{|c|}{ Friends' ASB: boys vs. girls } \\
\hline Intercept & - & 0.24 & $0.05^{* *}$ & 0.09 & $0.04^{*}$ \\
\hline Linear slope & - & 0.02 & 0.08 & 0.01 & 0.06 \\
\hline Quadratic slope & - & -0.02 & 0.08 & -0.01 & 0.01 \\
\hline
\end{tabular}

Note. Dashes indicate that effect of gender was not tested.

${ }^{*} p<.05{ }^{* *} p<.01$. 
antisocial behavior of class 1 GBG-children (see Table II). The size of this effect, $d=1.1$, was large (Cohen, 1988).

Control-group children who traveled along the moderate antisocial trajectory affiliated with friends who paralleled their own antisocial behavior. In contrast to these control-group children, GBG-children on the moderate trajectory initially started to affiliate with higher antisocial children. This resulted in higher friends' antisocial behavior scores at ages 8 and 9 years for these children (see Table II). After age 9, intervention-group children on the moderate antisocial trajectory affiliated with less antisocial friends. At age 10, intervention- and control-group children who followed the moderate developmental trajectory again affiliated with similarly antisocial children. It is of interest that GBG-children on the high antisocial trajectory (class 1) and GBG-children on the moderate antisocial trajectory (class 2) chose similarly low antisocial friends at age 10. A significant effect of male gender on the intercept of friends' antisocial behavior was found, indicating that boys in this trajectory class affiliated with friends who had higher levels of antisocial behavior than girls within this trajectory (see Table III). Boys and girls on the low antisocial trajectory affiliated with low antisocial friends, regardless of whether they were in the control- or intervention-group.

The percentages of children who were rejected by their peers from ages 7-10 years are presented in Table II. The reduction in antisocial behavior of children on the high antisocial behavior trajectory was accompanied by lower levels of peer rejection. Seventy-five percent of the control-group children on the high antisocial trajectory were rejected by their peers at age 10 years. This percent- age was $40 \%$ for their intervention-group counterparts. Children following the moderate and low antisocial behavior trajectory had low and very low to absent probabilities, respectively, of being rejected by their peers, regardless of intervention.

\section{Correlates and Consequences: Impact of the GBG Intervention}

Means of peer-nominated perpetration and selfreported victimization of overt and relational bullying at 10 years of age and self-reported anxious/depressed problems, attention problems, and aggressive behavior at 11 years of age are presented in Table IV. We first tested for differences between intervention- and controlgroup children through MANOVA. All variables were entered simultaneously. The interaction term between GBG and trajectory class was significant indicating differences between intervention- and control-group children within classes. Separate MANOVAs were performed to assess the differences between intervention- and control-group children within each class.

Intervention children who started off on the high antisocial trajectory had lower levels of relational bullying at age 10 years than their control-group counterparts. The friends they affiliated with had lower levels of relational bullying than the friends of control-group class 1 children. Intervention children also had lower levels of self-reported aggressive behavior at age 11 years. The effect sizes of these positive results were all large (Cohen, 1988).

Intervention children who followed the moderate antisocial trajectory had lower levels of relational bullying and were less often a victim of overt and relational

Table IV. Peer-Nominated and Self-Reported Means and Effect Sizes of Mean Difference of Relational Bullying, Victimization, and Emotional andb Behavior Problems for Children Following a High, Moderate, and Low Developmental Trajectory

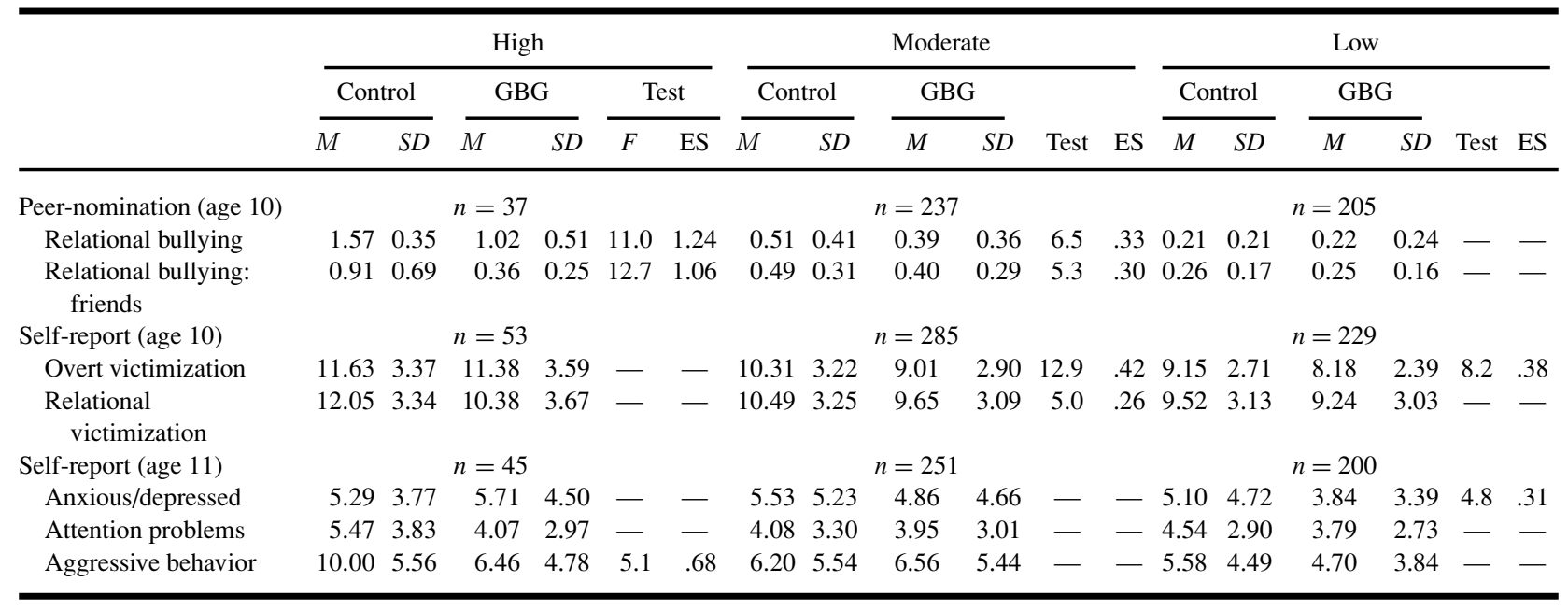

Note. Only tests and effect sizes of means significantly different at $p<0.5$ are given. GBG $=$ Good Behavior Game. ES $=$ Effect Size (Cohen's $d$ ). 
bullying than their control-group counterparts. The friends they affiliated with had lower levels of relational bullying. The sizes of these effects were in the small to medium range (Cohen, 1988).

Low antisocial children (class 3) who attended GBG classrooms were less often a victim of relational bullying than their control-group counterparts. In addition, these children reported lower levels of anxious/depressed problems. The sizes of these positive effects were always in the small to medium range (Cohen, 1988).

\section{DISCUSSION}

The aim of this study was to test developmental theory with a preventive intervention and to understand the mechanisms of change in the development of antisocial behavior. We additionally facilitated prevention science by studying the impact of the universal GBG intervention on the developmental trajectories of antisocial behavior and on two components that are closely associated with antisocial behavior - the affiliation with deviant friends and peer rejection. The GBG was implemented in ordinary elementary schools. Teachers received the standard amount of training and supervision while implementing the GBG (i.e., teachers received no special treatment because of the study). Consequently, implementation fidelity was not perfect, as described by van Lier et al. (2004), but may be considered normal given the real life conditions in which the study was carried out. The results showed that children who started off on the high antisocial behavior trajectory had large reductions in the level of antisocial behavior and cooccurring behaviors, due to intervention. The processes through which these reductions in antisocial behavior were achieved are a test of theories of the development of antisocial behavior. The reductions in antisocial behavior coincided with affiliation with less deviant friends and by lower percentages of peer rejection. These results thus showed a reciprocal relationship between the development of antisocial behavior, the affiliation with deviant peers, and peer rejection. These findings support a causal role of deviant friends and peer rejection in the development of antisocial behavior.

This study provided insight into the mechanisms that are associated with reductions in high-level antisocial behavior. Two findings are of importance. First, the reductions in antisocial behavior among the high-risk children coincided with changes among normatively developing children. Children following the high developmental trajectory decreased in their antisocial behavior. These changes cooccurred with prolonged interactions with children who followed the moderate antisocial behavior trajectory. With time, GBG children on the moderate and high antisocial behavior trajectories started to select friends with similar levels of antisocial behavior (i.e., they started to select friends who also traveled along each developmental trajectory). The majority of boys in the sample followed the moderate antisocial trajectory. We therefore considered this trajectory normative for boys. As a result, high antisocial GBG children, who are almost always boys, remained in contact with normatively developing boys. This was in contrast with control-group children where high antisocial children selected increasingly deviant friends (i.e., increasingly selected friends who also traveled along the high antisocial behavior trajectory). Elliott et al. (1985) proclaimed that weak bonding to conventional peers facilitates the drift toward similarly deviant friends. This prolonged interaction and bonding with normative boys and resulting opportunities for learning appropriate behaviors from these boys, may have caused the highly antisocial children to change their behavioral styles of coercion and antisocial behavior. Pairing aggressive with nonaggressive peers has been proven effective in the reduction of aggression (Hektner, August, \& Realmuto, 2003). The improvement in their behavior may also explain why GBG children who started off on the high developmental trajectory were much less likely to be rejected by their peers compared to control-group counterparts.

Second, the results suggest that the affiliation between normatively and deviantly developing children was initiated by the normatively developing children. All children indicated who they liked most at each assessment. The initial increase in friends' antisocial behavior scores of GBG-children on the moderate antisocial trajectory suggests that these children actively sought contact with children on the high level developmental trajectory-it were normatively developing boys who chose children on the high antisocial trajectory as their friends. GBGchildren on the high antisocial trajectory initially did not seek friendships with less antisocial peers than controlgroup children on this trajectory. This suggests that it is the reaching out by normatively developing boys to high antisocial boys that resulted in the friendships between the children following the moderate and high developmental trajectories. Previous studies that have addressed mechanisms of change in antisocial behavior have focused on high-risk samples only (e.g., Bierman et al., 2002; Lochman \& Wells, 2002; Vitaro et al., 1999, 2000). This study goes beyond these previous ones by showing that both changes within high-risk children and changes within normatively developing children may account for the chain of processes leading to the reductions in antisocial behavior of high-risk children. We therefore need 
to study how interventions influence the developmental course of both at-risk and normatively developing children to fully understand the mechanisms of change in antisocial behavior.

The results are of importance for prevention science. Previous reports on GBG effectiveness were largely based on teacher reports (Kellam et al., 1994; Rebok, Hawkins, Krener, Mayer, \& Kellam, 1996; van Lier et al., 2004). This paper adds to this by reporting the effects of the GBG intervention on antisocial behavior reported by the children themselves. The goal of the Good Behavior Game was to create a safe and predictable classroom environment, which resulted in a number of clinically important positive effects. GBG-children who started off on a high antisocial trajectory had large reductions in their antisocial behavior and had lower levels of relational bullying compared to control-group children. This was substantiated by better outcomes in children following the moderate and low developmental trajectories. The reductions in bullying and victimization in moderately antisocial children and the reductions in victimization and of anxious/depressed problems in low antisocial children all indicated a classroom environment in which children felt safer. The reduction in victimization and anxious/depressed feelings among low- risk children warrants further attention. Studies on the effectiveness of the GBG and other preventive intervention programs targeting disruptive behavior have, understandably, focused on reductions in targeted behaviors. Victimization and, especially, internalizing behavior problems are less well studied. This study showed, however, that an intervention aimed at improving the classroom environment is beneficial for all children, not just those who are in need of intervention, and results in positive effects on a variety of outcome variables, not just those directly targeted.

The positive and large effects found in children who started off on the high antisocial trajectory all indicate reductions in the risk these children run for later maladjustment problems. It is important to notice that only $10 \%$ of all children, almost all of them boys, followed this high antisocial trajectory. As stated earlier, controlgroup children on the high antisocial developmental trajectory had the highest levels of self-reported aggressive and delinquent behavior in late childhood (van Lier et al., 2004). This suggested that these children are at risk for developing other poor outcomes later in adolescence (Loeber, Green, Keenan, \& Lahey, 1995; MillerJohnson et al., 2002; Patterson et al., 2000) and adulthood (Kim-Cohen et al., 2003). The small number of children and the shape of the trajectory suggest these children are at risk for following a developmental path called "lifecourse persistent" (Moffitt, 1993) or "chronic" (Nagin \&
Tremblay, 1999). Many serious negative outcomes have been found for these children, including psychopathic personality traits (Moffitt, Caspi, Dickson, Silva, \& Stanton, 1996), juvenile delinquency (Broidy et al., 2003; Nagin \& Tremblay, 1999), and convictions for violent crimes in adolescence and adulthood (Jeglum-Bartusch, Lynam, Moffitt, \& Silva, 1997; Moffitt et al., 1996; Moffitt, Caspi, Harrington, \& Milne, 2002). The many and, in terms of effect size, large positive effects found for the GBG-children on the high antisocial path all suggest a reduction in the risk for such negative outcomes.

Finally, a number of findings from this study should be noted. No iatrogenic effects were found for the affiliation of moderately antisocial children with highly antisocial children. Such effects were reported by Dishion, Poulin, and Burraston (2001). The GBG appears to have prevented this expected iatrogenic effect. In addition, the results showed that children on the low antisocial trajectory did not seek contact with children following the moderate or high antisocial trajectories, regardless of intervention. An explanation appears to be that the moderate antisocial trajectory is normative for boys whereas the low antisocial trajectory is normative for girls. Boys and girls this age tend to seek friendships with their own sexes.

There are limitations to this study. First, peernominations of antisocial behavior were used. It has been argued that peer-nominations do not reflect actual behavior, but instead reflect children's perceptions of their classmates' behavior. However, van Lier and Crijnen (2005) reported high correlations between peer-nominations of antisocial behavior and teacher-reported externalizing problems. Moreover, in the same study it was found that teachers rated almost all of the children who followed a high developmental trajectory of antisocial behavior as having clinically elevated externalizing behavior. The present study showed that reductions in peer-nominated antisocial behavior coincided with the reductions on selfreported aggressive behavior. These findings all confirm that peer-nominations do represent actual behavior.

Second, children were only followed from ages $7-$ 11 years. The importance of the reductions in risk status due to intervention of children who started off on the high antisocial behavior trajectory still has to become apparent in adolescence. Third, dropping out of this study was related to higher levels of antisocial behavior at age 7 years old. The differential drop-out did however not impact the model-estimation and therefore did not seem to influence the findings of this study. Fourth, the findings of this study suggest that reductions in antisocial behavior in children on the high antisocial trajectory were mediated by the affiliation with normatively developing boys. Unfortunately, this mediation effect could not be statistically tested. Such 
methods are not yet available for growth mixture models (Muthén, personal communication, November 2004). Another methodological limitation was that the positive intervention impact on the outcome variables was tested using MANOVAs. These effects could have been more directly tested by incorporating them in the model. However, this made the already complex model unstable (e.g., different solutions obtained with random sets of starting values). Such analyses may have been possible with a larger sample.

Fifth, it is important to notice that classroom compositions generally do not change in elementary schools in The Netherlands. This is different from other countries and may have influenced the impact of the GBG. Through the stable classroom compositions, improvements due to intervention may have had more time to settle within the social system of the peer-group, which could have generated better results compared to school systems with nonstable classroom compositions. Alternatively, the negative consequence of reputation processes may be stronger in stable than unstable classroom compositions and can undermine the effectiveness of the GBG.

In summary, the present study used a number of methodological innovations to study the mechanisms inducing change in antisocial behavior. A preventive intervention was nested in a longitudinal study on multiple processes of development. The findings showed that:

1. The reductions in children's antisocial behavior coincided with affiliation with nondeviant peers and less rejection by mainstream peers. These findings support the hypothesis of a causal relation between these three processes?

2. The reductions in antisocial behavior in children who started off on the high antisocial trajectory coincided with an affiliation with normatively developing children. This affiliation was initiated by the normatively developing children who started selecting high-risk children as their friends. In our understanding of the mechanisms of change in antisocial behavior, we must therefore focus both on changes in these high-risk children, and on changes in the interaction between groups of children who follow different developmental paths of antisocial behavior;

3. The Good Behavior Game intervention resulted in a large number of clinically significant improvements in both externalizing and internalizing problems for children following different developmental trajectories of antisocial behavior. Especially the clinically significant improve- ments found for children following the high antisocial trajectory imply significant reductions in the risk for later maladjustment for these children.

\section{ACKNOWLEDGMENTS}

This study was supported by grants from the Sophia Foundation for Medical Research and the Ministry of Justice, The Netherlands.

\section{REFERENCES}

Achenbach, T. M. (1991). Manual for the Youth Self-Report and 1991 Profile. Burlington, VT: University of Vermont, Department of Psychiatry.

Asher, S. R., \& Parker, J. G. (1989). Significance of peer relationship problems in childhood. In B. H. Schneider \& G. Attili (Eds.), Social competence in developmental perspective. NATO Advanced Science Institutes series. Series D: Behavioural and social sciences (Vol. 51, pp. 5-23). New York: Kluwer Academic/Plenum.

Barrish, H. H., Saunders, M., \& Wolfe, M. D. (1969). Good Behavior Game: Effects of individual contingencies for group consequences and disruptive behavior in the classroom. Journal of Applied Behavior Analysis, 2, 119-124.

Bierman, K. L., Coie, J. D., Dodge, K. A., Greenberg, M. T., Lochman, J. E., McMahon, R. J., et al. (2002). Using the Fast Track randomized prevention trial to test the early-starter model of the development of serious conduct problems. Development and Psychopathology, 14, 925-943.

Boivin, M., \& Vitaro, F. (1995). The impact of peer relationships on aggression in childhood: Inhibition through coercion or promotion through peer support. In J. McCord (Ed.), Coercion and punishment in long-term perspectives (pp. 183-197). New York: Cambridge University Press.

Bongers, I. L., Koot, H. M., van Der Ende, J., \& Verhulst, F. C. (2004). Developmental trajectories of externalizing behaviors in childhood and adolescence. Child Development, 75, 1523-1537.

Broidy, L. M., Nagin, D. S., Tremblay, R. E., Bates, J. E., Brame, B., Dodge, K. A., et al. (2003). Developmental trajectories of childhood disruptive behaviors and adolescent delinquency: A six-site, crossnational study. Developmental Psychology, 39, 222-245.

Cicchetti, D., \& Toth, S. L. (1992). The role of developmental theory in prevention and intervention. Development and Psychopathology, 4, 489-493.

Cohen, J. (1988). Statistical power analysis for the behavioral sciences (2nd ed.). Hillsdale, NJ: Erlbaum.

Coie, J. D., Belding, M., \& Underwood, M. (1988). Aggression and peer rejection in childhood. In B. Lahey \& A. Kazdin (Eds.), Advances in clinical child psychology (Vol. 2, pp. 125-158). New York: Plenum.

Coie, J. D., Cillessen, A. H., Dodge, K. A., Hubbard, J. A., Schwartz, D., Lemerise, E. A., et al. (1999). It takes two to fight: A test of relational factors and a method for assessing aggressive dyads. Developmental Psychology, 35, 1179-1188.

Coie, J. D., \& Dodge, K. A. (1988). Multiple sources of data on social behavior and social status in the school: A cross-age comparison. Child Development, 59, 815-829.

Coie, J. D., \& Kupersmidt, J. D. (1983). A behavioral analysis of emerging social status in boys' groups. Child Development, 54, 14001416.

Coie, J. D., Terry, R., Lenox, K., Lochman, J., \& Hyman, C. (1995). Childhood peer rejection as predictors of stable patterns of adolescent disorder. Development and Psychopathology, 7, 697-713.

Conduct Problems Prevention Research Group. (1992). A developmental and clinical model for the prevention of conduct disorders: The 
FAST Track program. Development and Psychopathology, 4, 509527.

Conduct Problems Prevention Research Group. (2002). The implementation of the Fast Track program: An example of a largescale prevention science efficacy trial. Journal of Abnormal Child Psychology, 30, 1-17.

Crick, N. R. (1997). Engagement in gender normative versus nonnormative forms of aggression: Links to social-psychological adjustment. Developmental Psychology, 33, 610-617.

Crick, N. R., \& Grotpeter, J. K. (1996). Children's treatment by peers: Victims of relational and overt aggression. Development and Psychopathology, 8, 367-380.

Deater-Deckard, K. (2001). Annotation: Recent research examining the role of peer relationships in the development of psychopathology. Journal of Child Psychology and Psychiatry, 42, 565-579.

Dishion, T. J., Patterson, G. R., \& Griesler, P. C. (1994). Peer adaptations in the development of antisocial behavior: A confluence model. In L. R. Huesmann (Ed.), Aggressive behavior: Current perspectives (pp. 61-95). New York: Plenum.

Dishion, T. J., Poulin, F., \& Burraston, B. (2001). Peer group dynamics associated with iatrogenic effects in group interventions with highrisk young adolescents. New Directions for Child and Adolescent Development, 91, 79-92.

Dolan, L. J., Jaylan, T., Werthamer, L., \& Kellam, S. (1989). The Good Behavior Game Manual. Baltimore: The Johns Hopkins Prevention Research Center.

Dolan, L. J., Kellam, S. G., Brown, C. H., Werthamer-Larsson, L., Rebok, G. W., Mayer, L. S., \& et al. (1993). The short-term impact of two classroom-based preventive interventions on aggressive and shy behaviors and poor achievement. Journal of Applied Developmental Psychology, 14, 317-345.

Elliott, D. S., Huizinga, D., \& Ageton, S. S. (1985). Explaining delinquency and drug use. Beverly Hills, CA: Sage.

Elliott, D. S., \& Menard, S. (1996). Delinquent friends and delinquent behavior: Temporal and developmental patterns. In J. D. Hawkins (Ed.), Delinquency and crime: Current theories (pp. 28-67). New York: Cambridge University Press.

Fergusson, D. M., Wanner, B., Vitaro, F., Horwood, L. J., \& SwainCampbell, N. (2003). Deviant peer affiliations and depression: Confounding or causation? Journal of Abnormal Child Psychology, 31, 605-618.

Greenberg, M. T., Domitrovich, C., \& Bumbarger, B. (Eds.). (2001). The prevention of mental disorders in school-aged children: Current state of the field [entire issue]. Prevention and Treatment, 4.

Hektner, J. M., August, G. J., \& Realmuto, G. M. (2003). Effects of pairing aggressive and nonaggressive children in strategic peer affiliation. Journal of Abnormal Child Psychology, 31, 399412.

Ialongo, N., Poduska, J., Werthamer, L., \& Kellam, S. (2001). The distal impact of two first-grade preventive interventions on conduct problems and disorder in early adolescence. Journal of Emotional and Behavioral Disorders, 9, 146-160.

Ialongo, N. S., Werthamer, L., Kellam, S. G., Brown, C. H., Wang, S., \& Lin, Y. (1999). Proximal impact of two first-grade preventive interventions on the early risk behaviors for later substance abuse, depression, and antisocial behavior. American Journal of Coтmunity Psychology, 27, 599-641.

Jeglum-Bartusch, D., Lynam, D., Moffitt, T. E., \& Silva, P. (1997). Is age important: Testing general versus developmental theories of antisocial behavior. Criminology, 35, 13-47.

Kellam, S. G., \& Anthony, J. C. (1998). Targeting early antecedents to prevent tobacco smoking: Findings from an epidemiologically based randomized field trial. American Journal of Public Health, $88,1490-1495$.

Kellam, S. G., \& Rebok, G. W. (1992). Building developmental and etiological theory through epidemiologically based preventive intervention trials. In R. E. Tremblay \& J. McCord (Eds.), Preventing antisocial behavior: Interventions from birth through adolescence (pp. 162-195). New York: Guilford.
Kellam, S. G., Rebok, G. W., Ialongo, N., \& Mayer, L. S. (1994). The course and malleability of aggressive behavior from early first grade into middle school: Results of a developmental epidemiologicallybased preventive trial [published erratum appears in Journal of Child Psychology and Psychiatry 1994, 35: 983]. Journal of Child Psychology and Psychiatry, 35, 259-281.

Kim-Cohen, J., Caspi, A., Moffitt, T. E., Harrington, H., Milne, B. J., \& Poulton, R. (2003). Prior juvenile diagnoses in adults with mental disorder: Developmental follow-back of a prospective-longitudinal cohort. Archives of General Psychiatry, 60, 709-717.

Lacourse, E., Nagin, D., Tremblay, R. E., Vitaro, F., \& Claes, M. (2003). Developmental trajectories of boys' delinquent group membership and facilitation of violent behaviors during adolescence. Development and Psychopathology, 15, 183-197.

Lahey, B. B., Waldman, I. D., \& McBurnett, K. (1999). The development of antisocial behavior: An integrative causal model. Journal of Child Psychology and Psychiatry, 40, 669-682.

Lochman, J. E., Lenhart, L. E., \& Wells, K. C. (1996). Coping Power program: Child component. Unpublished manual. Durham, NC: Duke University Medical Center.

Lochman, J. E., \& Wells, K. C. (2002). Contextual social-cognitive mediators and child outcome: A test of the theoretical model in the Coping Power program. Development and Psychopathology, 14, 945-967.

Loeber, R., Green, S. M., Keenan, K., \& Lahey, B. B. (1995). Which boys will fare worse? Early predictors of the onset of conduct disorder in a six-year longitudinal study. Journal of the American Academy of Child and Adolescent Psychiatry, 34, 499-509.

Miller-Johnson, S., Coie, J. D., Maumary-Gremaud, A., \& Bierman, K. (2002). Peer rejection and aggression and early starter models of conduct disorder. Journal of Abnormal Child Psychology, 30, 217-230.

Miller-Johnson, S., Coie, J. D., Maumary-Gremoud, A., Lochman, J. E., \& Terry, R. (1999). Relationship between childhood peer rejection and aggression and adolescent delinquency severity and type among African American youth. Journal of Emotional and Behavioral Disorders, 7, 137-146.

Moffitt, T. E. (1993). Adolescence-limited and life-course-persistent antisocial behavior: A developmental taxonomy. Psychology Review, 100, 674-701.

Moffitt, T. E., \& Caspi, A. (2001). Childhood predictors differentiate life-course persistent and adolescence-limited antisocial pathways among males and females. Development and Psychopathology, 13, $355-375$.

Moffitt, T. E., Caspi, A., Dickson, N., Silva, P., \& Stanton, W. (1996). Childhood-onset versus adolescent-onset antisocial conduct problems in males: Natural history from ages 3-18 years. Development and Psychopathology, 8, 399-424.

Moffitt, T. E., Caspi, A., Harrington, H., \& Milne, B. J. (2002). Males on the life-course-persistent and adolescence-limited antisocial pathways: Follow-up at age 26 years. Development and Psychopathology, 14, 179-207.

Muthén, B. (2001). Second-generation structural equation modeling with a combination of categorical and continuous latent variables: New opportunities for latent class-latent growth modeling. In L. M. Collins \& A. G. Sayer (Eds.), New methods for the analysis of change (pp. 291-322). Washington, DC: American Psychological Association.

Muthén, B., \& Muthén, L. K. (2000). Integrating person-centered and variable-centered analysis: Growth mixture modeling with latent trajectory classes. Alcoholism: Clinical and Experimental Research, 24, 882-891.

Muthén, B., \& Shedden, K. (1999). Finite mixture modeling with mixture outcomes using the EM algorithm. Biometrics, 55, 463469.

Muthén, B. O., Brown, C. H., Masyn, K., Jo, B., Khoo, S. T., Yang, C. C., et al. (2002). General growth mixture modeling for randomized preventive interventions. Biostatistics, 3, 459475 . 
Muthén, L. K., \& Muthén, B. O. (1998-2004). Mplus. Statistical analyses with latent variables. User's guide (3.0 ed.). Los Angeles: Author.

Nagin, D., \& Tremblay, R. E. (1999). Trajectories of boys' physical aggression, opposition, and hyperactivity on the path to physically violent and nonviolent juvenile delinquency. Child Development, 70, 1181-1196.

Netherlands Central Bureau of Statistics. (1999). StatLine. Voorburg/ Heerlen: Netherlands Central Bureau of Statistics.

Patterson, G. R., Dishion, T. J., \& Yoerger, K. (2000). Adolescent growth in new forms of problem behavior: Macro- and micro-peer dynamics. Prevention Science, 1, 3-13.

Patterson, G. R., Reid, J. B., \& Dishion, T. J. (1992). Antisocial boys (Vol. 4). Eugene, OR: Castina.

Petras, H., Kellam, S., Brown, C. H., \& Ialongo, N. S. (2003). Effects of a universal first-grade classroom-based preventive intervention on the developmental paths and prevention of antisocial personality disorder in young adulthood. Paper presented at the Society for Prevention Research 11th Annual Meeting, Research to Policy, Washington, DC.

Rebok, G. W., Hawkins, W. E., Krener, P., Mayer, L. S., \& Kellam, S. G. (1996). Effect of concentration problems on the malleability of children's aggressive and shy behaviors. Journal of the American Academy of Child and Adolescent Psychiatry, 35, 193-203.

Reid, J. B., Eddy, J. M., Fetrow, R. A., \& Stoolmiller, M. (1999). Description and immediate impacts of a preventive intervention for conduct problems. American Journal of Community Psychology, 27, 483-517.

Storr, C. L., Ialongo, N. S., Kellam, S. G., \& Anthony, J. C. (2002). A randomized controlled trial of two primary school intervention strategies to prevent early onset tobacco smoking. Drug and Alcohol Dependence, 66, 51-60.

Tremblay, R. E., McCord, J., Boileau, H., Charlebois, P., Gagnon, C., Le Blanc, M., et al. (1991). Can disruptive boys be helped to become competent? Psychiatry, 54, 148-161.

van der Sar, A. M. (2002). Licentiemap Taakspel voor schoolbegeleiders. Rotterdam, The Netherlands: Pedologisch Instituut. van der Sar, A. M., \& Goudswaard, M. (2001). Docenthandleiding Taakspel voor basisonderwijs. Rotterdam, The Netherlands: Pedologisch Instituut.

van Lier, P. A. C., \& Crijnen, A. A. M. (2005). Trajectories of peer-nominated aggression: Risk status, predictors, and outcomes. Journal of Abnormal Child Psychology, 33, 99112

van Lier, P. A. C., Muthén, B. O., van der Sar, R. M., \& Crijnen, A. A. M. (2004). Preventing disruptive behavior in elementary schoolchildren: Impact of a universal, classroom-based intervention. Journal of Consulting and Clinical Psychology, 72, 467478.

van Lier, P. A. C., Vitaro, F., Wanner, B., Vuijk, P., \& Crijnen, A. A. M. (2005). Gender differences in the developmental links between antisocial behavior, friends' antisocial behavior, and peer rejection in childhood: Results from two cultures. Child Development, 76, 841-855.

Verhulst, F. C., van der Ende, J., \& Koot, H. M. (1997). Handleiding voor de Youth Self-Report [Manual for the Youth Self-Report]. Rotterdam, The Netherlands: Afdeling Kinder- en Jeugdpsychiatrie, Sophia Kinderziekenhuis/Academisch Ziekenhuis Rotterdam/Erasmus Universiteit Rotterdam.

Vitaro, F., Brendgen, M., Pagani, L., Tremblay, R. E., \& McDuff, P. (1999). Disruptive behavior, peer association, and conduct disorder: Testing the developmental links through early intervention. Development and Psychopathology, 11, 287-304.

Vitaro, F., Brendgen, M., \& Tremblay, R. E. (2000). Influence of deviant friends on delinquency: Searching for moderator variables. Journal of Abnormal Child Psychology, 28, 313325 .

Vitaro, F., Brendgen, M., \& Tremblay, R. E. (2001). Preventive intervention: Assessing its effects on the trajectories of delinquency and testing for mediational processes. Applied Developmental Science, $5,201-213$.

Wells, K. C., Lenhart, L. E., \& Lochman, J. E. (1996). Coping Power program: Parent component. Unpublished manual. Durham, NC: Duke University Medical Center. 